\title{
LA JERARQUÍA CATÓLICA ESPAÑOLA EN PERSPECTIVA COMPARADA La confrontación política entre la Iglesia y el Gobierno
socialista a comienzos del siglo XXI
}

\author{
THE SPANISH CATHOLIC CHURCH IN COMPARATIVE PERSPECTIVE \\ Political confrontation between the Church and the socialist government at \\ the beginning of the 21th Century
}

\author{
SUSANA AgUILAR saguilar@cps.ucm.es; susana@march.es \\ Universidad Complutense de Madrid. España
}

\begin{abstract}
RESUMEN
La Iglesia católica española (ICE) constituye un grupo de interés multi-issue con distintos resultados en su actividad política: la financiación y la educación son asuntos clave en los que está protegida por los Acuerdos de 1979, pero los poderes públicos no tienen la obligación de negociar con esta institución políticas de contenido moral. Como respuesta a la liberalización del aborto y a la aprobación del matrimonio de personas del mismo sexo, promovidas por el Gobierno de Rodríguez Zapatero, la ICE, a diferencia de otras instituciones eclesiásticas en Europa en situaciones parecidas, desarrolla una estrategia de confrontación junto con grupos católicos conservadores y, en menor medida, partidos políticos afines. Su posición "monopolista" en una sociedad que se define mayoritariamente como católica (argumento sociológico), la inextricable imbricación entre catolicismo e identidad nacional (argumento histórico) y su privilegiada relación con el Estado, que deriva de los Acuerdos de 1979 y del aconfesionalismo constitucional (argumento institucional), pueden explicar esta estrategia. Mientras que la Conferencia Episcopal (CE) es la principal responsable de la confrontación a nivel estatal, los obispos, a nivel autonómico, se han aprestado a través de un gran número de convenios con las autoridades regionales a defender los intereses de la lglesia y minimizar los posibles "daños" que derivan del ámbito estatal. El Estado autonómico ha multiplicado los puntos de acceso al sistema político para la Iglesia y podría suceder que la CE terminara perdiendo peso político a favor de las conferencias episcopales regionales, promovidas no solo por las iglesias periféricas nacionalistas sino, también, por la creciente relevancia del nivel autonómico frente al estatal para los intereses eclesiásticos.
\end{abstract}

Palabras Clave

Confrontación; España; Gobierno Zapatero; Grupo de interés; Iglesia católica.

\section{Abstract}

The Spanish Catholic church (SCC) conforms a multi-issue interest group with a heterogeneous political record: unlike finance and education, two key areas which are covered by the 1979 Agreements with the Vatican, moral policies need not be negotiated with public authorities. Responding to the liberalization of abortion and approval of same-sex marriage by the Zapatero government, the SCC, in contrast with other churches under similar political circumstances, has embarked upon a confrontation strategy in alliance with conservative Catholic groups and like-minded political parties. Its monopoly position in a society that still defines itself as predominantly Catholic (sociological argument), the inextricable link between Catholicism 
and national identity (historical argument) and its privileged relationship with the state, as a result of the 1979 Agreements with the Vatican state and its partially-established constitutional status (institutional argument) help understand this strategy. The Episcopal Conference $(E C)$ is the main responsible for confrontation at the state level while the bishops, at the regional one, have set out to defend church interests, and minimize the inflicted "damage", by means of a number of agreements with regional authorities. Thus, the EC might end up losing political power in favour of regional EC, promoted not only by local nationalist churches but also by the increasing relevance of the regional level for church interests.

\section{KEYWORDS}

Catholic Chuch; Confrontation; Interest Group; Spain; Zapatero Government.

"La Iglesia tiene el derecho de aprobar juicios morales incluso en asuntos que tocan el orden político, siempre que los derechos de la persona... hagan tales juicios necesarios" (Gaudium et Spes, Constitución Pastoral sobre la Iglesia en el Mundo Moderno, 1965).

\section{INTRODUCCIÓN}

Diversos autores han detectado en Europa una reactivación de los conflictos religiosos así como un aumento de la presencia de la religión en el ámbito político. La secularización, desigual pero innegable en la mayoría de los países europeos, puede por lo tanto ser compatible con el creciente protagonismo de la religión en la vida pública de esta región. El revival religioso podría estar vinculado a un determinado tipo de liderazgo religioso que elige desempeñar un visible papel político (explicación basada en la oferta) y/o a la movilización de los sectores sociales que exhiben una mayor práctica religiosa (explicación basada en la demanda). La disyuntiva entre teorías de demanda y oferta religiosa resultaría entonces innecesaria. Prueba de ello es que, aunque la sociedad española exhibe síntomas inequívocos de secularización, la Iglesia católica y ciertos grupos laicos próximos a la misma han relanzado estrategias de confrontación política en los albores del nuevo siglo.

El presente trabajo se enmarca en el análisis sociopolítico del hecho religioso desde el lado de la oferta: la atención se centra en el papel político de la Iglesia católica española (ICE) en democracia, principalmente durante las dos legislaturas del Gobierno

Agradezco a Isidro Catela (director de la Oficina de Información de la Conferencia Episcopal española), Mercedes Cabrera (ex Ministra de Educación del Gobierno de Zapatero), Alejandro Tiana (ex Secretario General de Educación del Gobierno de Zapatero), Fernando Burrea (ex Subsecretario de Educación del Gobierno de Zapatero), Jordi Pedret (vocal en la Comisión de Justicia desde 1986, excepto durante la 4. ${ }^{\text {a }}$ legislatura), Ignacio García-Juliá (director del Foro de la Familia), Víctor Rodríguez Gago (director de comunicación de Hazte Oír) y Mercedes Coloma (presidenta de Cofapa, Confederación de Padres de Alumnos) que me hayan permitido entrevistarles para la realización de este trabajo. 
socialista de Rodríguez Zapatero. Con contadas excepciones, el estudio de las iglesias y del liderazgo religioso en la contienda electoral y la movilización política en contextos democráticos europeos ha sido escasamente abordado en las ciencias sociales. Aquí se aspira a contribuir a este campo de estudio a través de la consideración de la ICE como grupo de interés que persigue mantener (en circunstancias críticas) o aumentar (en circunstancias favorables) su influencia en el sistema político a través de la adopción de decisiones racionales y cálculos estratégicos. Previamente, el trabajo desarrolla aquellos factores contextuales —el tipo de mercado religioso, el estatus constitucional de la Iglesia, y la identificación histórica entre catolicismo y Estado nación-que pueden ayudar a entender cómo la ICE se concibe a sí misma, así como su particular elección de estrategias políticas. También se analizan las consecuencias que la creación de la Conferencia Episcopal (CE) ha tenido para la Iglesia y se sitúa a la jerarquía eclesiástica en una perspectiva europea. El porqué se activa el conflicto religioso a partir de finales de los años noventa y cuáles son los repertorios de actuación de la ICE y de sus obispos serán objeto de análisis en el último apartado. El presente trabajo se ha basado en fuentes secundarias (sociología política, electoral y de la religión, ciencia política y relaciones internacionales, historia y periodismo político) y primarias (encuestas, censos religiosos, prensa, páginas web...), pero se ha beneficiado, principalmente, de la realización de entrevistas en profundidad con actores del ámbito religioso, político-administrativo y social.

\section{LA FALSA ALTERNATIVA ENTRE TEORÍAS DE DEMANDA Y OFERTA RELIGIOSA}

La teoría de la secularización (TS) ha sido el paradigma dominante en la sociología de la religión durante los años sesenta y setenta. Mientras que la TS parecía explicar bien el panorama europeo, el caso norteamericano no se ajustaba a este paradigma. Por ello, aparecieron otras teorías que, poniendo el énfasis en la oferta religiosa (el tipo de liderazgo y mercado religiosos), daban cuenta del excepcionalismo norteamericano. Las teorías de la elección racional y la movilización de recursos, que se centran en la oferta y tienen su origen en EE.UU, han competido así con la TS que, desarrollada básicamente en Europa, gira en torno a la demanda o los consumidores de la religión.

Más allá de que ambos tipos de teorías hayan podido surgir para explicar fenómenos distintos, la TS se ha visto sometida a crítica desde los años ochenta. En una perspectiva comparada que no se circunscriba a las democracias liberales occidentales, el caso europeo de alta secularización, y no el norteamericano de baja, sería la excepción y no la regla. Es más, ni siquiera Europa se ha convertido de forma gradual e imparable en una región secularizada, no solo porque en la misma convivan países sobresecularizados (Alemania del Este y la República Checa), infrasecularizados (Polonia e Irlanda), y de resistencia a la secularización (Italia y Portugal), sino porque, además, el fenómeno 
religioso se ha revitalizado en ciertos lugares (Rumania y Rusia, entre otros). Esta disparidad ha provocado que uno de los más conocidos defensores de la TS, Peter Berger, haya reconocido su fracaso: "lo que yo y la mayoría de los sociólogos de la religión escribimos en la década de 1960 acerca de la secularización era un error". Dos años después, el mismo autor identificaba en Europa "una fuerte supervivencia de la religión [...] a pesar de la extendida alienación con respecto a las iglesias organizadas" (Katzenstein 2006:7-8).

El impacto de la religión en el comportamiento electoral lleva siendo objeto de análisis desde los años cuarenta y el cleavage religioso ha competido en importancia con el de la clase social a la hora de explicar las decisiones partidistas de grupos sociales y ciudadanos. Durante las últimas décadas, además, se ha constatado un creciente interés por el estudio de la influencia de la religión en asuntos muy diversos (Marshall 2011; Ferrari 2007; Esping-Andersen 1990; Lane y Ersson 2005). Asimismo, diversos autores coinciden en señalar que en Europa se asiste a una reactivación de los conflictos religiosos y a una mayor presencia de la religión en la esfera pública (Casanova 1994; Warner 2000; Madeley 2003; Minkenberg 2003; Katzenstein 2006). Parece posible, por lo tanto, que la secularización no sea incompatible con el creciente protagonismo de la religión en la vida política europea, lo cual podría deberse a dos razones:

la existencia de un liderazgo religioso activo en los asuntos políticos (que puede operar en mercados religiosos distintos), lo que conduce a una explicación basada en la oferta,

la existencia de sectores sociales con una alta práctica religiosa que, aun siendo minoritarios en muchos países, desarrollan una visible actuación política, lo que nos lleva a una explicación basada en la demanda.

Ambas explicaciones pueden combinarse o no, aunque en el caso español aparecen unidas: la jerarquía eclesiástica (los obispos, colegiados en la $\mathrm{CE}$ ) y ciertos grupos sociales católicos próximos a la misma han desarrollado una importante movilización en contra de las reformas de contenido moral promovidas por el Gobierno de Rodríguez Zapatero.

\section{ESPAÑA COMO CONFIRMACIÓN DE LA TEORÍA DE LA SECULARIZACIÓN}

En el trabajo de Pérez-Nievas y Cordero (2011), que recoge las tendencias religiosas en 31 países (desde 1980 a 2008 para la mayoría) a partir de la Encuesta Europea de Valores, España aparece como un país que ha experimentado una clara secularización: el porcentaje de población que no se adscribe a ninguna religión habría subido del 9 al 20\%, el de asistencia religiosa semanal a los oficios habría bajado del 40 al 
$15 \%$, el que afirma la relevancia de Dios disminuiría del 61 al $49 \%$, así como el que deposita confianza en la Iglesia: del 24 al 10\%. A pesar de ello, España no es uno de los países más secularizados, sobre todo si se compara el indicador de adscripción a alguna Iglesia (20\% de no adscritos en 2008 ) con el de los Países Bajos (51\%), Gran Bretaña (50\%), Francia (50\%), o Bélgica (36\%); en los otros indicadores las diferencias no serían tan acusadas pues, frente a, por ejemplo, el $15 \%$ de españoles que en el 2008 afirmaba tener una práctica religiosa semanal, habría un 11\% de holandeses, un $17 \%$ de británicos, un $7 \%$ de franceses y un $18 \%$ de belgas. La principal diferencia entre la secularización española y la europea es que la primera ha ocurrido más tarde y a un ritmo más rápido.

Los datos del CIS, que se centran en la evolución temporal de la práctica y adscripción religiosas de los españoles, confirman esta secularización (Tabla 1).

Tabla 1.

Asistencia a los oficios e identificación religiosa en España (1985-2008).

\begin{tabular}{|c|c|c|c|c|c|c|}
\hline & 1985 & 1989 & 1994 & 2005 & 2008 & $2008-1985$ \\
\hline \multicolumn{7}{|c|}{ Asistencia a misa (solo católicos) } \\
\hline Nunca & 37,3 & 22,8 & 27,4 & 39,3 & 56,6 & $+19,3$ \\
\hline Varias veces al año & 21,1 & 31,4 & 17,3 & 14,5 & 16,5 & $-4,6$ \\
\hline $2 / 3$ veces al mes & 12,5 & 12,8 & 11,6 & 9,0 & 10,1 & $-2,4$ \\
\hline Todos los domingos & 28,0 & 28,4 & 26,1 & 16,3 & 16,8 & $-11,2$ \\
\hline \multicolumn{7}{|l|}{ Identificación religiosa } \\
\hline $\mathrm{N} .{ }^{\circ}$ total católicos & 100 & 90,3 & 83,3 & 79,4 & 78,1 & $-21,9$ \\
\hline $\begin{array}{l}\mathrm{N} .{ }^{\circ} \text { total no } \\
\text { creyentes/ateos } \\
\text { indiferente }\end{array}$ & $\mathrm{Ns} / \mathrm{nc}$ & 8 & 12,8 & 17 & 18,2 & $+10,2$ \\
\hline
\end{tabular}

Fuente: A partir de Martín y Tsirbas (2011).

Estos datos, y muchos otros que no se abordarán por falta de espacio, han conducido a diversos sociólogos a hablar del católico nominal (Requena 2008), del poscatólico (González-Anleo 2008), de la superficial marca "soy católico" (Elzo 2008), del escéptico religioso (Bericat 2008), del descatólico (Díaz-Salazar 2005) o del cristiano libre y autónomo (Pérez Vilariño y Schoenherr 1990). Este panorama coincide, además, con el análisis pesimista que la propia ICE hace del creyente español: incluso Juan Pablo II se refirió al "neopaganismo español" (Manuel y Mac Leish 2006:62). 


\section{Mercado ReLIGIOSO, estatus CONSTITUCIONAL E IDENTIDAD CULTURAL}

\section{Un mercado religioso monopolista y homogéneo}

Las teorías de la oferta en su variante de elección racional se centran principalmente en el tipo de mercado religioso, que puede ser monopolista, duopolista y pluralista 0 de competencia múltiple. El mercado religioso en España es monopolista porque la ICE agrupa a la inmensa mayoría de los ciudadanos que se adscriben a una religión. El "indice de fragmentación religiosa", que señala la probabilidad de que dos personas elegidas al azar puedan practicar religiones distintas o no adherirse a ningún credo, es por lo tanto muy bajo e indica que el mercado es enormemente homogéneo (Lane y Ersson 1999). Aunque las encuestas del CIS sobre adscripción religiosa solo incluyen a las personas con nacionalidad española, en el país viven unos cinco millones y medio de extranjeros (Instituto Nacional de Estadística 2009), de los cuales, en torno a un millón proceden de países musulmanes, otro millón o menos de países ortodoxos, y el resto, de países cristianos de diverso tipo (católicos, luteranos, evangelistas...). El relativo crecimiento de las religiones no católicas se ha producido principalmente debido al aumento de la inmigración; es decir, la gran mayoría de los españoles que han dejado de identificarse como católicos no han abrazado otras religiones sino que se han secularizado.

Para el caso de las Iglesias católicas en Europa, España, Italia, Portugal, Polonia, Irlanda, Austria y, en menor medida, Francia, serían claros ejemplos de mercado religioso monopolista; Alemania, Bélgica y los Países Bajos representarían el duopolio, pues el catolicismo comparte mercado con variantes del protestantismo; y la modalidad pluralista, por último, estaría ausente. Los teóricos de la acción racional afirman que la libre competencia en los mercados religiosos es positiva porque, "el éxito de las empresas religiosas dependerá de su habilidad a la hora de satisfacer a sus clientes". La no competencia "favorece que las instituciones religiosas se vuelvan holgazanas y carezcan de los incentivos necesarios para proporcionar sus servicios de forma eficaz" (Norris e Inglehart 2004:11; Aldridge 2000:103-4). Las teorías de la oferta se ajustan bien al caso norteamericano pero no al europeo, no solamente porque en el continente la adscripción religiosa es más estable (un $40 \%$ de los norteamericanos ha cambiado alguna vez de Iglesia), sino, sobre todo, porque las Iglesias católicas europeas en mercados monopolistas no exhiben, generalmente, la apatía política u holgazanería que podría esperarse de las mismas en las condiciones de ausencia de competencia en las que operan. Sí se encuentran, sin embargo, comportamientos de bajo activismo político en las iglesias protestantes situadas en mercados religiosos también monopolistas (en la región nórdica pero también en la Iglesia anglicana de Inglaterra). Esta pauta puede explicarse mediante el conocido argumento de Lipset y Rokkan (1967) que recalca cómo el luteranismo, en sus distintas variantes y allí donde triunfó, se alió de forma temprana con los poderes temporales y se convirtió en Iglesia nacional a partir del siglo XVII. Así pues, la identidad religiosa y también la participación política vinculada a la religión 
pueden ser más intensas, en condiciones iguales de monopolio, en los países católicos que en los protestantes. Y, lo que es más interesante aún, no todas las Iglesias católicas se comportan igual en las mismas (España vs Portugal) o en parecidas situaciones de mercado (España vs Bélgica): "Ias Iglesias nacionales varían considerablemente en cuanto al énfasis de sus enseñanzas y el alcance y la naturaleza de su implicación política" (Manuel, Reardon y Wilcox 2006:2).

\section{El estatus constitucional y los Acuerdos de 1979}

En las postrimerías del franquismo, tanto los obispos como el clero coincidieron en no reclamar la separación Iglesia-Estado (Callahan 2000). Durante la etapa de debate constitucional hubiera sido impensable mantener la confesionalidad del Estado pero la ICE recalcó su "oposición al estilo americano de separación Iglesia-Estado" (Anderson 2003:140). Esta oposición se recogió en el art. 16.3, según el cual España es un Estado aconfesional. Sin embargo, como la mayoría de los españoles son católicos, las autoridades se obligan a mantener "las consiguientes relaciones de cooperación con la Iglesia católica y las demás confesiones". El aconfesionalismo no se entiende como neutralidad religiosa ya que, entre otras cosas, los Acuerdos entre el Estado español y la Santa Sede de 1979 (los Acuerdos de 1979) otorgan un estatus especial a la ICE. Estos Acuerdos, que sustituyen al Concordato de 1953, resultaron más ventajosos para los intereses de la Iglesia que el ambiguo e impreciso texto constitucional. Los Acuerdos de 1979 recogen un documento de 1976 y cuatro de 1979, siendo estos últimos: 1) un Acuerdo Jurídico; 2) un Acuerdo sobre Enseñanza y Asuntos Culturales, que incorpora el tema de los medios de comunicación; 3) un Acuerdo sobre Asuntos Económicos; y 4) un Acuerdo sobre la Asistencia Religiosa a las Fuerzas Armadas y Servicio Militar de Clérigos y Religiosos. Tres del total de los cinco Acuerdos fueron aprobados por mayoría, "pero el PSOE y el PCE se opusieron al acuerdo que trataba tanto de la educación como al de la financiación" (Callahan 2000:554).

El trato de favor hacia la ICE no es sin embargo tan excepcional en una perspectiva comparada: Ios diferentes contextos regulativos Iglesia/Estado, en Europa, coinciden en ofrecer una "quimera de neutralidad" (Madeley 2003:4). El caso francés, en cuanto a separación Iglesia-Estado, es bastante anómalo, ya que la mayor parte de los países se colocan en una posición intermedia (partial establishment/disestablishment), situándose las Iglesias de Estado (full established) protestantes de la región nórdica en el otro extremo. Como señala Minkenberg (2003), esta posición intermedia puede incrementar el margen de maniobra de los líderes religiosos y resultar más adecuada a la hora de defender sus intereses. En relación a las Iglesias católicas, la combinación de partial establishment/disestablishment, monopolio en el mercado religioso y doctrina social de larga tradición, favorece la adopción de un papel político activo. Este puede transformarse en rol de adversario político si concurren otros dos factores: la existencia de una identidad nacional históricamente definida como católica y la percepción de amenazas importantes en la agenda del Gobierno. Ambos factores caracterizan el caso español y ayudan a entender la estrategia política de la ICE desde comienzos del siglo XXI. 


\section{Identidad nacional y catolicismo cultural}

La construcción del Estado nación español está ineludiblemente vinculada al catolicismo. Casanova señala que la Reconquista "condujo a una temprana identificación de la identidad religiosa y nacional [...] La Inquisición iba a jugar una función de creación estatal" (1994:73). Al igual que en Italia, las fuerzas liberales del siglo XIX eligen una estrategia secular y se alían con los intereses urbano-comerciales con el objetivo de centralizar y modernizar el aparato estatal (Lipset y Rokkan 1967). La fe se convierte ahora en "impedimento a la hora de construir la nación y transforma los conflictos políticos modernos en guerras de religión" (Casanova 1994:77). Los privilegios de la Iglesia alcanzan su punto álgido durante el franquismo (nacional-catolicismo), aunque el dictador se arroga la potestad de decidir con respecto al nombramiento de los obispos. La otra cara de una mayoritariamente ultramontana jerarquía eclesiástica fue el rampante anticlericalismo, plasmado en la quema de iglesias y asesinato de religiosos, desde la década de 1830 hasta finales de los años treinta del siglo XX.

La históricamente enraizada presencia del catolicismo en la sociedad y la política españolas y su íntima conexión con la identidad nacional han contribuido sin duda a que un alto porcentaje (78\%) de españoles se siga actualmente declarando católico a pesar de que la práctica religiosa haya descendido drásticamente. La relación entre identidad religiosa y nacional no es un fenómeno exclusivo de España: ocurre en el resto del sur de Europa, en Irlanda y Polonia (aunque en estos casos la identidad nacional católica ha sido una forma de resistencia a la dominación extranjera) (Manuel et al. 2006:5), y en países nórdicos como Dinamarca donde "la fidelidad a la Iglesia luterana es una expresión de identidad nacional" (Voyé 2004:200). La religión sería para muchos europeos tanto un legado cultural como un atributo colectivo que les distingue de los inmigrantes principalmente musulmanes. Lo característico del caso español es que el argumento sociológico (el hecho de que la mayoría de los españoles se autoidentifiquen como católicos) ha sido y es constantemente esgrimido por la ICE para justificar su estatus privilegiado, así como sus reivindicaciones y ataques a determinadas políticas.

\section{LA ICE COMO GRUPO DE INTERÉS EN LA ESPAÑA DEMOCRÁTICA}

\section{La creación de la Conferencia Episcopal}

La ICE constituye uno de los mejores ejemplos de exitosa adaptación institucional a contextos políticos dispares en la historia de España. La jerarquía eclesiástica ha operado de forma temprana como un grupo de interés que perseguía mantener (en circunstancias adversas), o aumentar (en circunstancias favorables), su influencia política mediante la adopción de decisiones racionales. Su racionalidad está por supuesto limi- 
tada (bounded rationality), como la de otros actores que operan en la esfera pública, por diversos factores como los costes de información y las consecuencias no intencionales de sus acciones. Algunos autores han señalado que con "organizaciones tan perfectas como una Iglesia jerarquizada [...], la racionalidad de los fines [...] y la congruencia de los medios es generalmente sobrestimada" y que "la heterogeneidad de los elementos constitutivos del catolicismo español contribuye fuertemente a esta ausencia de perspectivas firmes" (Hermet 1985:18). Sin embargo, esta heterogeneidad no es un factor tan importante porque los elementos ajenos a la jerarquía (clero, órdenes religiosas, organizaciones laicas...) nunca han tenido un papel relevante en la negociación con los poderes públicos. Lo que sí resulta importante en cuanto a la exhibición de una estrategia política crecientemente integrada y uniforme, es el cambio organizativo que conlleva la creación de la CE en 1964 que convierte gradualmente a la Iglesia en un auténtico grupo de interés moderno.

Durante gran parte del periodo franquista, el episcopado funcionó de forma monárquica (con la preeminencia absoluta del arzobispo-primado de Toledo) a través de una Conferencia de Metropolitanos creada en 1923 y que se caracterizó por su escasa cohesión. Como resultado del Concilio Vaticano II, este órgano fue sustituido por la CE, la cual comenzará su andadura en 1966 sin llegar a ser nunca reconocida por el dictador. Según los Acuerdos de 1979, la CE tiene personalidad jurídica civil y es el único interlocutor oficial de la Iglesia con el Estado. Gracias a este cambio, la Iglesia "aparece cada vez más [...] como un interlocutor política e ideológicamente coherente y unificado [...] [que transmite] la expresión colectiva de los obispos" (Hermet 1985:175). "Las conferencias episcopales son un ejemplo de lo que la Iglesia denomina colegialidad episcopal [y] no son nuevas" en la historia del catolicismo. Aunque asociadas al Concilio Vaticano II, comienzan a crearse "en la primera mitad del siglo XIX con el auge del estado-nación moderno y la separación Iglesia-Estado" (Yamane 2005:21). Lo que sí hizo el Concilio, además de promover el aggiornamento de la Iglesia, fue incitar a una mayor participación crítica de esta institución en los asuntos sociales y políticos (Gaudium et Spes, Dignitatis Humanae) a través precisamente de estas conferencias (Christus Dominus).

Los grupos de interés han sido definidos como "los representantes de subgrupos específicos de la sociedad que se vinculan con partidos políticos para ser representados en el proceso político", "organizaciones que no son parte del gobierno sobre el que están intentando influir", y "organizaciones formales, basadas exclusivamente en la adhesión individual voluntaria, que procuran influir en las políticas públicas en su propio beneficio sin asumir responsabilidad de Gobierno" (Warner 2000:18; Berry 1997:4-5; Mattina 2010:13). A pesar de que la Iglesia católica es evidentemente un grupo de interés, lo es de forma peculiar: a) aunque para estos grupos la capacidad de representación o el membership "es un recurso importantísimo, las encuestas muestran que la mayoría de los católicos en muchos países se oponen [entre otros temas] a la postura de la Iglesia sobre la contracepción" (Manuel et al. 2006:4); b) tras el Concilio Vaticano II, además, la Iglesia no suele vincularse con ningún partido de manera explícita; c) de forma total- 
mente atípica rinde cuentas a un "gobierno extranjero" (el Vaticano) que negocia en un plano de igualdad formal con los gobiernos nacionales; y, finalmente, no se basa strictu sensu en la adhesión voluntaria: la entrada en la institución (a través del bautismo) no la decide el individuo sino generalmente la familia. Por último, la relación de la Iglesia católica con la democracia es complicada porque muchos de sus objetivos, los que conciernen sobre todo a la moral privada, son innegociables (Warner 2000).

A diferencia de la Iglesia norteamericana, cuyas conferencias episcopales estatales han adoptado una estructura dual en la que los obispos componen la junta directiva y los laicos (con amplia experiencia política y legislativa) forman, en su gran mayoría, el consejo de administración y se comportan como típicos lobbysts, la CE española y otras europeas carecen de un grado similar de profesionalización y de explícita orientación hacia las políticas públicas que les conciernen. En España, las reuniones entre el Gobierno estatal y la Iglesia se celebran generalmente en comisiones formadas por entre seis y diez personas, siendo el número de interlocutores el mismo para cada uno de los dos sectores. A un nivel más alto existen también reuniones paritarias entre la máxima instancia de la CE y el vicepresidente del gobierno, así como, si existen asuntos diplomáticos que resolver, entre el presidente del gobierno y el nuncio papal. La CE es indudablemente la protagonista a la hora de discutir aquellos temas que son tratados por los Acuerdos de 1979 (principalmente, la educación y la financiación), pero el gobierno no tiene por qué convocarla (ni la CE puede acogerse a ningún mecanismo político 0 legal para solicitar reuniones) cuando surgen otros asuntos espinosos, referidos sobre todo a cuestiones morales ${ }^{1}$. Con relación por ejemplo al matrimonio para personas del mismo sexo y la liberalización de la ley del aborto, no ha habido reuniones entre la CE y el Gobierno. Esta ausencia de contactos contrasta enormemente con las intensas negociaciones asociadas a las reformas educativas del primer Gobierno de Rodríguez Zapatero. Este hecho parece confirmar que la principal prioridad política de la ICE se sitúa en el campo educativo (Pérez-Agote 2005; Barreiro 2000), pero también apunta a la innegable obligación que tiene el gobierno de convocar a la iglesia cuando surgen temas que están recogidos en un tratado internacional. Los Acuerdos de 1979 han permitido que la CE en las negociaciones con el Gobierno haya podido llegar a afirmar que es "sujeto de derecho internacional revestido de autoridad estatal" ante el estado español (Entrevista con Tiana 2011).

A pesar de la visibilidad política de la CE, es este un actor colectivo que no puede imponer una estrategia a sus miembros, los obispos, que son autónomos en sus respectivas diócesis y responsables únicamente ante el Vaticano. El número de miem-

\footnotetext{
${ }^{1}$ En la Comisión de Justicia del Congreso, que ha tratado temas tan relevantes como el "matrimonio gay", la despenalización del aborto o la apostasía, la Iglesia no ha sido convocada (a diferencia de la profusa presencia de las conferencias episcopales estatales norteamericanas en los hearings organizados por sus respectivas cámaras legislativas) ni ha presionado directamente a ningún diputado —a diferencia, de nuevo, de las anteriores conferencias (Yamane 2005). (Entrevista con Pedret 2011).
} 
bros de la CE puede variar: a los obispos jubilados (que tienen voz pero no voto) hay que añadir los que están en activo. Además, este número no coincide con las 67 diócesis que existen en el país, pues en cada una de ellas existe un obispo residente que puede solicitar o no obispos auxiliares. En diciembre del 2010, la CE estaba compuesta por 113 obispos, de los cuales 39 estaban jubilados. Como órgano de coordinación, la CE funciona para servir a los obispos, que pueden disentir de sus comunicados, y no al revés. El disenso es de todos modos muy limitado porque la CE persigue infatigablemente llegar a decisiones consensuadas antes de que se hagan públicas: de más de 100 votaciones, solo se ha producido un máximo de nueve votos negativos desde $1966^{2}$. Las reglas de decisión dependen del tema objeto de discusión y la transparencia no es la norma de estas reuniones (las actas del comité ejecutivo y de las asambleas plenarias son secretas) pero, a veces, se producen filtraciones a la prensa. Tal vez para evitar este problema, la CE comenzó hace cuatro años a informar acerca de los resultados de determinadas votaciones. Asimismo, y de forma paulatina, se han organizado conferencias de prensa para presentar ciertas campañas publicitarias al tiempo que el informe económico de la ICE se dio a conocer a los medios por primera vez en 2009 (Entrevista con Catela 2010).

La posición oficial de la CE no solo se ve condicionada por la autonomía de los obispos sino también por la intervención del Vaticano. A partir de la elección de Juan Pablo II, este comenzó a nombrar obispos conservadores e intentó controlar más de cerca estas conferencias. La política del presidente de la CE desde 1987, Suquía, de marginar a los obispos para operar en estrecha cooperación con el nuncio papal, condujo prácticamente a una rebelión de los mismos (Callahan 2000; Himes 2006). Finalmente, la CE no puede tampoco imponer directrices a las órdenes religiosas: muchas de estas operan en centros educativos y caritativos de CC.AA con las que tienen acuerdos financieros, lo cual puede limitar su lealtad a la CE. "A finales de los ochenta, estas órdenes aportaban personal a 1545 hospitales, orfanatos y centros de tercera edad bajo administración eclesiástica directa y proporcionaban 20.510 profesores al sistema escolar católico. También tenían religiosos en 127 instituciones públicas de salud en manos de gobiernos regionales" (Callahan 2000:622). Un buen ejemplo de la dificultad con la que se topa la Iglesia a la hora de "forzar el consenso" ha sido la controvertida asignatura Educación para la Ciudadanía. Contrariando la oposición a la misma por parte de la CE, la FERE (Federación Española de Profesores de Religión) publicó sus propios libros de texto, recibiendo el entonces responsable de la misma, Manuel de Castro, así como el director de SM (editorial católica Santa María), Javier Cortés, durísimos ataques por su postura conciliadora, tanto por parte de la CE como, principalmente, de aquellos grupos católicos más conservadores (Entrevistas con Tiana y Burrea 2011).

\footnotetext{
${ }^{2}$ Una prueba de desacuerdo fue que nueve obispos votaran en contra de la Constitución. Más recientemente, se ha registrado un disenso "récord", con siete noes, respecto del documento "Evaluación moral del terrorismo", acordado en 2002.
} 


\section{La ICE y la competencia electoral}

A pesar de su incomparable éxito adaptativo a lo largo de la historia, la llegada de la democracia obliga a la ICE a redefinir sus estrategias políticas. A diferencia de las Iglesias católicas en Italia y Alemania tras la II Guerra Mundial, que defendieron el voto por formaciones políticas concretas (Warner 2000), la ICE no lo hará. El clima posterior al Concilio Vaticano II, la falta de unidad de las formaciones demócrata-cristianas en España (Hunneus 1985), y la neutralidad política que logra imponer el cardenal Tarancón explican este hecho. Neutralidad no es lo mismo, sin embargo, que indiferencia política: la ICE siempre ha expresado de manera indirecta sus preferencias partidistas, sin nombrar a ningún partido, antes de los distintos comicios (Aguilar 2010). Aun así, la jerarquía ha sido consciente de que, al tiempo que "se espera que los estados sean neutrales en el plano religioso, también [se espera] que las iglesias sean políticamente imparciales. Aunque es raro que los líderes religiosos se vean constreñidos en su actividad política por la ley, la agitación partidista directa [por parte de los mismos] es frecuentemente percibida como incompatible con el funcionamiento de la democracia" (Enyedi 2003:227).

Más que expresar afectos políticos, lo que la iglesia ha hecho público de forma evidente es expresar sus desafectos: por ejemplo, durante los años ochenta la CE dejó claro que los católicos no debían votar por partidos que incluyeran el aborto en sus programas. Por ello, y aunque la ICE tiene indudables preferencias políticas, éstas podrían entenderse mejor como preferencias por "el menos malo de los partidos". Cuando los gobiernos han mostrado una postura acomodaticia hacia el estatus quo religioso, tal y como sucedió durante la primera fase de la Transición (1976-82) y la etapa Aznar (1996-2004), la ICE ha adoptado un perfil político relativamente bajo. La opción por un perfil alto, que va asociado generalmente a una estrategia conflictiva, se ha producido siempre que los obispos han percibido amenazas importantes en las agendas gubernamentales. Estas amenazas se vinculan principalmente a temas de moral privada, ya que la financiación de la institución eclesiástica y la educación son asuntos que han quedado "blindados" en gran medida por los Acuerdos de $1979^{3}$.

El Estatuto de las Escuelas (1980) y la Ley del Divorcio (1981) crearon tensiones dentro del Gobierno de la UCD y molestaron evidentemente a la ICE. También creó fricciones el creciente nacionalismo de los obispos vascos y el tardío comunicado de la CE de rechazo al intento de golpe de estado (Callahan 2000:577). A pesar de su indudable proximidad a la Iglesia, la UCD disfrutó de un considerable grado de autonomía (Huneeus 1985; en Pérez-Agote 2008). La relación entre el Gobierno del PSOE de González (1982-96) y la ICE fue mucho más problemática y se caracterizó por epi-

\footnotetext{
${ }^{3}$ En palabras de la exministra Cabrera, la CE siempre esgrimió los Acuerdos de 1979 como forma de justificar su desacuerdo con la LOE. La negociación fue inexistente porque la CE actuaba como "un muro" y desoía el argumento de que la ley había sido aprobada por el Parlamento. Coinciden con esta idea Tiana y Burrea, que hablan de un "diálogo de sordos" y de los Acuerdos como de una "camisa de fuerza".
} 
sodios de dura confrontación verbal seguidos de contactos y negociaciones a veces secretos - no en vano, el entonces presidente del Gobierno había señalado la cuestión religiosa como uno de los cuatro "males de la Patria" (en Iglesias 2003:795). González, además, se negó "durante años enteros" a recibir al cardenal Suquía, Presidente de la CE (Ortega 1992:115), aunque sí se entrevistó con su anterior responsable, Díaz Merchán, que intentó "que la LODE no siguiera adelante" (Maravall, en Iglesias 2003) 4 . Díaz Merchán remarcó que los socialistas "no hablaban el mismo lenguaje en cuanto a la enseñanza en los colegios católicos, la asignatura de religión en las escuelas públicas, la familia, y la aplicación de los Acuerdos de 1979". De forma franca, el obispo admitió que "ellos no confiaban en nosotros... y nosotros no confiábamos en ellos" (en Catela 2008:158) $)^{5}$. Asimismo, los prelados estaban convencidos del doble juego de los socialistas para "reducir [la Iglesia] al ámbito cultural privado por medio de su proyecto político" (en González-Anleo 1999:38). Dejando a un lado el siempre espinoso tema de la educación, un importante ejemplo de falta de entendimiento fue la ley del aborto (1985) y la asociada "guerra de los catecismos" (Barreiro 2000), así como la alineación de la Iglesia con AP cuando pidió la abstención en el referéndum sobre la OTAN.

Con la llegada al poder del PP en 1996 se inicia una etapa menos conflictiva EstadoIglesia: el propio monseñor Rouco reconocía en 1998 que con los gobernantes conservadores "se habla bien, se dialoga bien", al tiempo que el entonces presidente de la CE, Elías Yanes, señalaba que había encontrado a Aznar más receptivo que a González (en Iglesias 2007:712-805) ${ }^{6}$. Hay que recordar que tras la derrota electoral de la UCD en 1982, solo quedó un partido en el ámbito nacional que reclamara una orientación cristiana, Alianza Popular, refundido como PP en 1989. Además, a diferencia de Tarancón y Díaz Merchán, que mantuvieron las distancias con AP, Suquía, elegido Presidente de la CE en 1987, junto con el nuncio papal, Tagliaterri, "actuaron en la sombra para promover la transformación de AP en una organización más centrista a imagen de los partidos demócrata-cristianos en Europa" (Callahan 2000:594). A pesar de compartir posturas en una amplia serie de temas, el PP y la ICE airearon también sus diferencias en dis-

\footnotetext{
${ }^{4}$ Según Maravall, la Iglesia utilizó al general Lacalle -jefe de la Junta de Jefes de Estado Mayor- para entregar dos "escritos contra la LODE a Felipe González" (Iglesias 2003:48).

5 "Relaciones nunca rotas pero nunca confiadas"... "presentadas como malas por la iglesia y tenazmente ponderadas como buenas por el Gobierno" (Ortega 1992:108). Alfonso Guerra ha señalado que mantuvo "una magníica relación personal con los señores de la CE", a pesar de "algunas violencias verbales", (Iglesias: 2003:749). Sin embargo, el vicepresidente de la CE en ese momento, Delicado Baeza, remarcó que el vicepresidente anunció que no habría entendimiento entre la Iglesia y el Gobierno en los ámbitos de la familia y la educación (Catela 2008).

${ }^{6}$ Según Martín Patino, exsecretario de Tarancón: "da la impresión de que los obispos están más a gusto con este gobierno [del PP] que con los socialistas"; "después de los problemas que tuvieron con los gobiernos socialistas, los obispos se encuentran ahora, con el PP, más acogidos, mejor tratados. Yo creo que cuando el Gobierno actual elabora una ley que de alguna manera puede afectar a la Iglesia, consulta con los obispos, cosa que no se les ocurría hacer a los socialistas" (en Iglesias 2007:564).
} 
tintos momentos: el Gobierno de Aznar, por ejemplo, se negó a renegociar el acuerdo financiero con la Iglesia, no revocó la ley del aborto ni cambió el estatus de la asignatura de religión en la escuela pública (Catela 2008). La dura política del partido en temas de inmigración provocó la crítica de ciertas figuras eclesiásticas al tiempo que la iglesia nunca apoyó la intervención española en la guerra de Irak. En cuestiones morales, sin embargo, el PP se mostró próximo a las preocupaciones eclesiásticas y su ley de educación (LOCE) fue del agrado de la ICE.

\section{La ICE en perspectiva comparada. Las Iglesias europeas y la política}

En relación con políticas de contenido moral, como el aborto, las protestas más recientes en Europa han estado protagonizadas no por las Iglesias sino por redes políticas (Prolife Alliance en Gran Bretaña), advocacy coalitions de abogados y médicos (en Francia), y grupos sociales desvinculados de la jerarquía religiosa (Alemania). En el primer país, la oposición a la propuesta de reformar el aborto en los años noventa provino principalmente "de alianzas políticas concretas más que de las iglesias". En el caso francés, la fuerte tradición laicista pareció limitar la visibilidad de la Iglesia católica que "se mantuvo bastante ausente del debate [sobre el aborto]" en los años setenta y ochenta (Minkenberg 2003:210-1), de hecho, las asociaciones antiabortistas católicas y protestantes francesas incorporaron "principios de neutralidad en sus estatutos: principios no-religiosos y no-políticos" (Parkes 1999:286). La liberalización del aborto en Alemania en 1992 colocó a la Iglesia católica en una incómoda posición: oficialmente rechazaba la nueva legislación "pero al mismo tiempo no quería perder la oportunidad de aconsejar a las mujeres y recibir por ello dinero público". El conflicto resultante se resolvió a favor de una "aproximación nacional y la decepción del Vaticano ante la postura de los obispos alemanes" (Minkenberg 2003:212). Por otro lado, en Bélgica, la Iglesia católica se ha opuesto a reformas políticas similares a las aprobadas por el Gobierno de Rodríguez Zapatero pero no ha escogido una estrategia de movilización conflictiva (Botterman y Hooghe 2009). En contraposición a estos casos, el sur de Europa muestra un escenario diferente. El voto religioso en Portugal, por ejemplo, que podría haber sido activado en relación a una serie de temas morales, no ha sido relevante hasta bien entrado el siglo XXI (Jalali y Vargas 2012), El sistema de partidos, centrado principalmente en dos formaciones políticas (PS y PSD) que no muestran diferencias ideológicas relevantes en asuntos relevantes para la iglesia, no ofreció a las elites políticas los incentivos necesarios para jugar la carta religiosa (Montero, Calvo y Martínez 2008). Sin embargo, "el período 2005-9 marcó un cambio considerable vis a vis las pautas anteriores, con el surgimiento finalmente del cleavage religioso entre la izquierda y la derecha en las elecciones del 2009" (Jalali y Vargas 2012:32). En Italia, por otra parte, el referéndum en torno al aborto organizado en los ochenta sí opuso a la DC y sus formaciones afines frente a los partidos opositores. Es más, la desaparición de la DC en 1993 se ha visto acompañada por una mayor frecuencia de conflictos en torno a temas religiosos y morales al tiempo que "la 
Conferencia de obispos italianos ha participado de forma creciente en el ámbito político", indicando a los electores católicos qué votar (como sucedió en el referéndum de 2005 que perseguía revocar la ley de Berlusconi que prohibía la fertilización in vitro), y apoyando manifestaciones de organizaciones católicas (como la contraria al proyecto del Gobierno de Prodi que pretendía legalizar de facto las uniones homosexuales) (Rinaldi et al. 2010:2). Tanto en Portugal como en Italia, y de manera similar a España, los mercados religiosos son monopolistas y las identidades nacionales han estado fuertemente vinculadas al catolicismo mayoritariamente dominante en sus respectivas sociedades.

\section{La ICE durante el Gobierno de Rodríguez Zapatero}

La variante de la teoría de la oferta religiosa que se utiliza en este trabajo afirma que la religión en las sociedades secularizadas puede convertirse en un asunto público si existen instituciones o elites religiosas que deciden desempeñar un papel político activo. La protesta contra temas de contenido moral no es sorprendente en democracia, pero sí lo es el muy distinto rol que las iglesias puedan desempeñar en el ámbito público. A diferencia de otras Iglesias católicas en Europa, pero de forma similar a la italiana, la ICE ha desarrollado un papel de adversario político. Aunque puedan mencionarse razones exógenas para esta implicación política (la lucha contra la secularización que inicia Juan Pablo II), ello no explicaría la diferente postura adoptada por las distintas instituciones católicas europeas. Por ello, y para entender el caso español, es necesario centrarse en razones endógenas estructurales que combinan factores históricos (la conexión entre catolicismo y estado-nación), sociológicos (la predominante posición de la ICE en el mercado religioso) e institucionales (la privilegiada relación Iglesia-Estado). Todas ellas explican la visión que la ICE tiene de sí misma: la iglesia se concibe como la defensora de la identidad católica española y como la garante última de un marco político y legislativo que incorpore los valores cristianos de la mayoría de los españoles. Otras razones endógenas de tipo coyuntural, tales como la progresiva definición del perfil religioso de los partidos y la activación del voto religioso, ayudan asimismo a entender esta estrategia.

Durante los años ochenta, los líderes políticos renunciaron a incorporar asuntos religiosos potencialmente conflictivos en sus agendas. Sin embargo, "desde mediados de los años noventa el voto religioso se ha vuelto más visible y se vincula precisamente a una cierta clarificación del perfil religioso de los principales partidos" (Calvo, Martínez y Montero 2010:4). Esta clarificación se constata en la agenda del Gobierno de Rodríguez Zapatero, centrada principalmente (sobre todo antes de la crisis económica de 2008-9) en la ampliación de los derechos y libertades civiles (Calvo 2009). Junto con la aprobación del denominado divorcio exprés, la reforma del código civil que permitió el matrimonio para personas del mismo sexo, la liberalización de la ley del aborto, la legislación 
relativa a la igualdad y protección de las mujeres, la ley de reproducción asistida y la ley de memoria histórica ${ }^{7}$, los socialistas se han embarcado también en reformas educativas y han anunciado un programa laicista. Aunque la cuestión educativa tuvo que ser negociada con la ICE y el progreso hacia una "España laica" ha sido aparcado, la CE ha considerado estas iniciativas un ataque frontal a los valores cristianos $y$ ha organizado una serie de campañas mediáticas en su contra, al tiempo que ha apoyado la protesta de distintos grupos sociales. Estos grupos se nutren de sectores católicos conservadores que probablemente mantienen una frecuente asistencia a los oficios y exhiben una alta intensidad de preferencias frente a cuestiones morales. Formarían parte, además, de una "minoría activa católica" ya identificada en los años noventa por autores como Toharia y Díaz Salazar (en González-Anleo 56:1999). La movilización católica también está conectada con una mayor presencia de la religión en las decisiones electorales, un hecho que se vincula asimismo a la progresiva clarificación del perfil religioso de los partidos. A pesar de que "el número total de votantes religiosos ha ido disminuyendo a lo largo del tiempo, es ahora más fácil encontrar votantes que usan su religiosidad como base de su apoyo a los partidos conservadores"... en la izquierda, "la ideología compensa el efecto negativo de la religiosidad de forma que es muy probable que incluso aquellos votantes izquierdistas que exhiben un alto nivel de asistencia a la iglesia voten por el PSOE" (Calvo, Martínez y Montero 2010:28-36).

Junto a sus aliados sociales, la ICE ha seguido atentamente la actuación de los partidos políticos en los temas morales. El récord de los partidos con una importante composición demócrata-cristiana ha sido sin embargo mixto: si se compara el PP (que se define como una "formación política centrista" vinculada a la tradición liberal española) con CiU (que contiene a UDC, partido que reconoce explícitamente su "inspiración cristiano-demócrata") y, sobre todo, con el PNV (que remarca su naturaleza "aconfesional y humanista"), el primero es el que ha mostrado la estrategia más consistente en la defensa de los "valores cristianos". Las votaciones parlamentarias reflejan este récord: la reforma vinculada al matrimonio de personas del mismo sexo obtuvo un resultado del 187/147 (todos los representantes del PP, excepto uno, los cuatro de UDC y algunos del PNV votaron en contra), mientras que la ley de liberalización del aborto consiguió una aprobación más ajustada de 184/158 (el PP, UPN, CC, y siete miembros de CiU — cuatro de ellos de UDC_- votaron en contra). Por ello, el $\mathrm{PP}$, como principal partido de la oposición a nivel nacional, constituye claramente el "menos malo" de los aliados políticos para la ICE a la hora de luchar contra la agenda del gobierno de Rodríguez Zapatero.

\footnotetext{
${ }^{7}$ Los obispos han denunciado la ley de memoria histórica (2007) porque supuestamente reabre heridas cerradas y dificulta la reconciliación de las "dos Españas" (Catela 2008).

${ }^{8}$ www.pp.es; www.unio.org; www.eaj-pnv.eu.
} 


\section{Las Estrategias Políticas de la ICE}

La estrategia de adversario político de la ICE se ha reflejado en un amplio repertorio de actuaciones: desde la organización de conferencias de prensa, hasta la puesta en práctica de campañas publicitarias (como las del 2009 y 2010 en contra de la reforma del aborto), la justificación de la desobediencia civil (señalando la legitimidad de la objeción de conciencia de los padres ante Educación para la Ciudadanía) y el apoyo (o, en ocasiones, promoción directa) a las movilizaciones en la calle. El radicalismo de ciertos pronunciamientos de la jerarquía eclesiástica ha calentado el ambiente político y dado el pistoletazo de salida a la protesta de los grupos católicos conservadores: el Arzobispo de Valencia, García Gasco, declaró antes de las elecciones de 2008 que las medidas del PSOE "[conducían] a la disolución de la democracia" (http://ecodiario.eleconomista.es; consultado el 15 de marzo 2011 ), mientras que la CE señalaba que la agenda socialista perseguía "excluir a los católicos de la vida pública" (www.conferenciaepiscopal.es) ${ }^{9}$. Prueba de que la ICE y el PP podrían tener intereses electorales compartidos sería el apoyo de los gobiernos conservadores en Madrid y Valencia a la rebelión política de ciertos católicos contra Educación para la Ciudadanía ${ }^{10}$. También lo sería que la CE criticara duramente el reconocimiento de una organización terrorista como mediador político, en alusión al fracasado intento de negociar un alto el fuego con ETA durante el primer mandato de Rodríguez Zapatero (iniciativa que fue también contundentemente denunciada por el PP) ${ }^{11}$.

La estrategia de confrontación de la ICE se ha centrado en torno a alianzas con partidos afines y, principalmente, grupos católicos conservadores de nueva creación como el Foro de la Familia, Hazte Oír y Profesionales por la Ética. Aunque puedan compartir intereses políticos, las alianzas entre estos actores no son formales ni explícitas. La CE no organiza las movilizaciones callejeras por mucho que a las mismas puedan unirse figuras eclesiásticas ${ }^{12}$. De forma similar a como han actuado los antiabortistas en Fran-

9 "Orientaciones morales ante la situación actual de España", Asamblea Plenaria 88, 23 de noviembre 2006)

10 El entonces Presidente de la CE, Blázquez, sí dio el visto bueno a la asignatura y sus contenidos fueron pactados con la FERE. Pero la aprobación de Blázquez fue soslayada por el vicepresidente de la CE, Cañizares, y por su secretario, Martínez Camino. Blázquez también había aceptado la LOE y ello facilitó el apoyo a la misma por parte de CiU y PNV (Entrevistas con Tiana y Burrea 2011).

${ }^{11}$ Esta crítica es particularmente ilustrativa porque la CE se ha negado pública y repetidamente a llamar a filas a los obispos vascos cuando éstos han pedido en distintas ocasiones que se abrieran negociaciones con ETA. En 1981, por ejemplo, el presidente de la CE, Díaz Merchán, declaró que "la Conferencia no tenía intención de discutir la autoridad de los prelados locales [vascos] a la hora de proporcionar ayuda pastoral a los creyentes de sus diócesis" (Callahan 2000:582).

${ }^{12}$ Según Catela (Entrevista 2010), son los grupos laicos los que han iniciado los contactos con la CE. Xavier Novell, el obispo más joven de España, ha declarado que solo "si los fieles laicos convocan alguna manifestación de importancia realmente fuerte, como la defensa de la vida, me lo plantearía [salir a la calle]. Pero en principio pienso que los obispos no deben asistir gratuita y fácilmente a manifestaciones públicas en 
cia y otros países europeos, los grupos españoles, que se definen como de inspiración cristiana, son extremadamente cautelosos a la hora de recalcar que son aconfesionales y apolíticos; también han remarcado que sus acciones son "protestas civiles" en las que no se admiten adhesiones de partidos políticos o iglesias (Entrevistas con García-Juliá y Rodríguez Gago, 2010). Este framing de la protesta no puede esconder, sin embargo, que han existido contactos previos entre la CE (o determinados obispos), ciertas figuras políticas y los grupos sociales convocantes, así como que es evidente un fenómeno de overlapping membership entre laicos católicos y órdenes religiosas.

Tabla 2.

Acción Colectiva en Relación con el "Matrimonio Gay"

\begin{tabular}{|c|c|c|c|c|c|}
\hline Fecha & $\begin{array}{l}\text { Repertorio y marcos } \\
\text { cognitivos }\end{array}$ & $\begin{array}{l}\text { Número de } \\
\text { participantes }\end{array}$ & Promotor & Grupos Sociales e ICE & $\begin{array}{l}\text { Partidos } \\
\text { Políticos }\end{array}$ \\
\hline $18 / 06 / 05$ & $\begin{array}{c}\text { Manifestación } \\
\text { "La Familia sí importa" } \\
\text { "Por la Libertad y la } \\
\text { Familia" } \\
\text { "Por el Derecho a una } \\
\text { Madre y a un Padre" }\end{array}$ & $\begin{array}{l}\text { Grande } \\
(622.000)\end{array}$ & $\begin{array}{l}\text { El Foro de } \\
\text { la Familia }\end{array}$ & $\begin{array}{l}\text { La Red Madre, } 18 \text { Obispos } \\
\text { y el Cardenal Rouco (apoyo } \\
\text { de líderes musulmanes y } \\
\text { Judíos), E-Cristians, HO, } \\
\text { Asociación Internacional de } \\
\text { Familias Unidas }\end{array}$ & $\begin{array}{c}\text { Líderes del } \\
\text { PP } \\
\text { (no Rajoy) }\end{array}$ \\
\hline 30/06/05 & $\begin{array}{l}\text { Concentración } \\
\text { "Por la Familia" }\end{array}$ & $\begin{array}{l}\text { Pequeña } \\
(4666)\end{array}$ & Foro & & \\
\hline $27 / 02 / 07$ & Congreso Paralelo & & Foro & & \\
\hline $30 / 12 / 07$ & $\begin{array}{l}\text { "Misa por la Familia } \\
\text { Cristiana" }\end{array}$ & $\begin{array}{l}\text { Grande } \\
(622.046)\end{array}$ & ICE & $\begin{array}{c}\text { Cardenal Rouco y varios } \\
\text { obispos }\end{array}$ & \\
\hline $30 / 12 / 09$ & $\begin{array}{l}\text { "Misa por la Familia } \\
\text { Cristiana" }\end{array}$ & $\begin{array}{l}\text { Mediana } \\
(178.000)\end{array}$ & $\begin{array}{l}\text { ICE y } \\
\text { Foro }\end{array}$ & & \\
\hline
\end{tabular}

Aunque las reformas educativas en España se han visto acompañadas de una movilización impresionante que dimana, principalmente, de la capacidad de la Concapa para activar a los padres de colegios católicos concertados ${ }^{13}$, es en el ámbito de las reformas que afectan a la moral privada en el que la ICE necesita de aliados políticos y, sobre todo, sociales que puedan sacar a la calle a la sociedad católica conservadora. Porque este ámbito no se encuentra blindado por ningún tratado y, además, es aquél en el que el católico nominal, predominante en España, se encuen-

la calle" (El País Semanal 16-1-2011). Rouco ha señalado que "solo en casos límite, en los que los derechos fundamentales de las personas estuvieran tan radicalmente amenazados [...] es posible que la Iglesia tuviera que convocar una manifestación" (Iglesias 2007:710).

${ }^{13} \mathrm{La}$ significativa presencia de la ICE en el sistema educativo constituye sin duda un importante mecanismo de movilización: en 2009/10, existían 5080 colegios católicos en los que estudiaban 1.423 .445 alumnos. 
tra más distante de la postura oficial de la iglesia: en un estudio del CIS de 2008 ( $n .^{\circ}$ 2752 ), el $60 \%, 62,1 \%$ y $51,7 \%$ de los encuestados se mostraba en contra de la ICE en los temas del aborto, el matrimonio homosexual y la adopción de niños por parejas gay, respectivamente ${ }^{14}$.

A pesar de que la movilización ha acontecido en muy distintas ciudades, Madrid ha sido el lugar privilegiado de la protesta católica ${ }^{15}$.

Tabla 3.

Acción Colectiva en Relación con el Aborto

\begin{tabular}{|c|c|c|c|c|c|}
\hline Fecha & Repertorio y marcos cognitivos & $\begin{array}{l}\text { Número de } \\
\text { participantes }\end{array}$ & Promotor & $\begin{array}{c}\text { Grupos } \\
\text { Sociales e ICE }\end{array}$ & $\begin{array}{l}\text { Partidos } \\
\text { Políticos }\end{array}$ \\
\hline $17 / 10 / 08$ & $\begin{array}{l}\text { Concentración frente a la sede del PSOE } \\
\text { "España es Vida","Viva España" }\end{array}$ & 200 & $\begin{array}{l}\text { Alternativa } \\
\text { Española }\end{array}$ & & \\
\hline $23-29 / 03 / 09$ & "Semana por la Vida" & & & & \\
\hline $26-7 / 03 / 09$ & $\begin{array}{l}\text { Il Reunión de Acción Mundial de } \\
\text { Parlamentarios y Gobernantes por } \\
\text { la Vida y la Familia, Protección de } \\
\text { la Mujer, Protección de la Vida }\end{array}$ & $\begin{array}{l}\text { Más } \\
\text { de } 120\end{array}$ & $\begin{array}{l}\text { World } \\
\text { Action for } \\
\text { Life }\end{array}$ & $\begin{array}{l}\text { Universidad } \\
\quad \text { San } \\
\text { Pablo-CEU }\end{array}$ & \\
\hline $29 / 03 / 09$ & $\begin{array}{l}\text { Manifestación en distintos lugares } \\
\text { "Marcha por la Vida" } \\
\text { "Aborto, Bibiana, no me da la } \\
\text { gana" } \\
\text { "No hay derecho a la muerte, hay } \\
\text { derecho a la vida" }\end{array}$ & $\begin{array}{l}\text { Mediana } \\
(109.600)\end{array}$ & $\begin{array}{c}\text { HO; } \\
\text { Derecho } \\
\text { a la Vida; } \\
\text { Grupos } \\
\text { pro-vida; } \\
\text { Médicos } \\
\text { por la Vida }\end{array}$ & Foro & $\begin{array}{l}20 \text { líderes del } \\
\text { PP (no Rajoy), } \\
1 \text { de UPN, y } 1 \\
\text { del PSOE }\end{array}$ \\
\hline $17 / 10 / 09$ & $\begin{array}{l}\text { Manifestación "Por la Vida, la } \\
\text { Mujer y la Maternidad. Todas las } \\
\text { Vidas cuentan" }\end{array}$ & $\begin{array}{l}\text { Grande } \\
(642.906)\end{array}$ & Foro & $\begin{array}{l}42 \text { grupos } \\
\text { sociales }\end{array}$ & $\begin{array}{c}\text { Importante } \\
\text { presencia de } \\
\text { líderes del PP } \\
\text { (no Rajoy pero } \\
\quad \text { sí Aznar) } \\
\end{array}$ \\
\hline 07/03/10 & $\begin{array}{l}\text { Concentración (en Madrid y más } \\
\text { de } 70 \text { ciudades) } \\
\text { "En Defensa de la Vida", "V por Vida" } \\
\text { "España, Sí a la Vida", } \\
\text { "Aído dimisión" "Ley del Aborto, } \\
\text { Ley Terrorista" }\end{array}$ & $\begin{array}{l}\text { Mediana } \\
(203.787)\end{array}$ & $\begin{array}{l}\text { Derecho a } \\
\text { la Vida }\end{array}$ & $\begin{array}{l}\mathrm{HO}+270 \\
\text { grupos sociales }\end{array}$ & $\begin{array}{l}\text { Importante } \\
\text { presencia de } \\
\text { líderes del PP } \\
\text { (no Rajoy) }\end{array}$ \\
\hline
\end{tabular}

${ }^{14}$ La existencia de una mayoría de opiniones "liberales" en asuntos morales es extraordinaria si se tiene en cuenta que un $95,1 \%$ de los españoles mayor de 18 años afirmaba en el 2002 que había tenido una educación católica (Santiago 2008:213).

${ }^{15}$ Agradezco a Juan Sevilla que me ayudara a recopilar información sobre las protestas callejeras. Como siempre sucede en este tipo de investigación, las discrepancias sobre número de participantes son enormes. Por ello, se ha utilizado la media aritmética y se ha clasificado las manifestaciones, y también las misas públicas organizadas por la ICE, como grandes (más de 500.000 participantes), medianas (de 50.000 a 500.000) y pequeñas (50.000 o menos). 


\section{La creciente relevancia política de los obispos frente a la CE}

La influencia política de la ICE tal vez deba ser analizada en términos de las actuaciones de los miembros de la CE, los obispos, más que en términos del actor colectivo que es la Conferencia: son los obispos los que realizan o no declaraciones políticas, deciden 0 no participar en manifestaciones públicas y optan o no por establecer contactos con los grupos católicos y los partidos afines en sus respectivos territorios. La organización descentralizada de la ICE en diócesis ha podido verse reforzada por el estado autonómico, aumentándose así aún más el margen de maniobra política de los obispos en detrimento de la CE que se ve obligada a funcionar de forma consensuada para presentar un frente unido de cara a la opinión pública. "La Iglesia vasca, catalana o andaluza se reúnen más a menudo y tratan temas más específicos e inmediatos que las reuniones más masivas y generales [de la CE]" (Laboa 1999:145). Los obispos, además, se deben a sus constituencies, lo cual explicaría las posturas nacionalistas de las Iglesias catalana y vasca: el obispo de Barcelona, Carles, mostró su enfado hacia la COPE porque alentaba "la crispación y [fomentaba] un discurso también hostil hacia Cataluña" y se ha declarado partidario de crear una región pastoral catalana ${ }^{16}$; por otro lado, el obispo de San Sebastián, Setién, pidió durante el Gobierno de Aznar que no se ilegalizara Batasuna al tiempo que señalaba que, para hablar con ETA, ésta no necesitaba dejar de seguir matando (en Iglesias 2007:231). Asimismo, "el desmembramiento de la diócesis de Lérida ${ }^{17}$ tiene una causa [nacionalista] y los temores desmentidos ante la posible provincia eclesiástica de Pamplona también" (Laboa 1999:145).

No obstante, el estado autonómico no es solo una potencial fuente de conflicto por las tendencias centrífugas que alimenta dentro de la ICE: también ofrece oportunidades políticas ya que los gobiernos regionales parecen ser más receptivos a las reivindicaciones eclesiásticas que el gobierno central. Las relaciones de los obispos con los políticos de las autonomías en las que se ubican sus diócesis son frecuentes pero generalmente se desarrollan en un plano informal (Entrevista con Burrea 2011), y pueden servir para dirimir tanto temas puntuales como para controlar asuntos más generales que afectan al desarrollo particular de la legislación aprobada por el Parlamento español. "Todos están de acuerdo en que resulta más fácil la relación de las Iglesias con los Gobiernos regionales" (Laboa 1999:146). El líder socialista, José Bono, afirma haber propiciado numerosas reuniones entre la cúpula del PSOE y la jerarquía católica (en Iglesias 2007:293). Según

\footnotetext{
${ }^{16} \mathrm{El}$ abad de Montserrat ha valorado "muy positivamente la actuación de algunos obispos que impidieron que se aprobara" en la CE un texto que defendía la unidad de España y atacaba la autodeterminación por ir en contra del cristianismo. Si se hubiera aprobado, "ese texto nos hubiera llevado a una polémica. Y ya tenemos bastantes polémicas en el interior de la Iglesia" (Iglesias 2007:761)

${ }^{17}$ En 1995 se aprobó la petición de la CE de transferir las 111 parroquias aragonesas de la diócesis de Lérida a la nueva diócesis de Barbastro-Monzón. Según el arzobispo de Tarragona, esta transferencia fue el resultado de la oposición de las parroquias aragonesas a la propuesta de creación de una Conferencia Episcopal catalana.
} 
el cardenal Rouco (1999:77): Ia Iglesia reconoce la nueva realidad política autonómica, especialmente con relación a aquellas políticas transferidas que son de su interés como "la enseñanza, cultura, sanidad, asuntos sociales, ordenación del suelo... Al verse implicados por las transferencias asuntos tratados y regulados en los Acuerdos con la Santa Sede, se hizo preciso abrir un nuevo camino para su aplicación a través de los contactos mutuos y de la negociación entre los obispos de las diócesis territorialmente afectadas y las autoridades competentes de dichas Comunidades. Esta vía se ha seguido prácticamente en todas las CC.AA con frutos prácticos evidentes, dada la cercanía a los problemas inmediatos y la mayor facilidad y flexibilidad en el diálogo mutuo".

En última instancia, si hubiera que determinar cuál es el grado de influencia política de la ICE, la respuesta dependería del a) tema en cuestión, b) ciclo político y c) nivel territorial.

A) De forma similar a como concluye Dahl en su clásico trabajo, Who Governs? (1961), ningún grupo de interés es capaz de dominar la política en una amplia variedad de issues. El hecho de que la ICE sea una organización multi-issue reduce su capacidad de influencia porque el abanico de temas que le afecta es muy alto, lo cual le obliga además a utilizar de forma subóptima sus recursos. Aunque la ICE es multi-issue, no se implica lógicamente de la misma forma (ni obtiene los mismos resultados) en todos los temas: financiación y educación son asuntos clave en los que, además, se siente protegida por los Acuerdos de 1979. Pero incluso aquí hay apartados en los que el margen de maniobra de las autoridades políticas es significativo: los cambios en cuanto a la situación de los profesores de religión y el estatus académico de esta asignatura, y la reciente obligación de la ICE de abonar el IVA, son prueba de ello. El apartado sobre los medios de comunicación de titularidad estatal que deben "garantizar el respeto de los sentimientos de los católicos", también recogido por los Acuerdos de 1979, se ha caracterizado por la aprobación de resoluciones que han sido insatisfactorias para la Iglesia tanto durante los Gobiernos del PSOE como del PP. En cuanto al patrimonio históricoartístico en posesión de la ICE, en 1997 se creó una comisión mixta Iglesia-Estado que se ha limitado básicamente al seguimiento del Convenio sobre las Catedrales. Por todo ello, mientras que el Acuerdo sobre Enseñanza "se desarrolla con un considerable grado de concreción", los relativos al patrimonio histórico-artístico y la presencia de la Iglesia en los medios de comunicación son "de carácter general" (Rouco 1999:71).

B) El ciclo político se relaciona con la presencia de gobiernos más o menos receptivos a las exigencias de la ICE y con la oportunidad que aquéllos pueden encontrar en determinadas coyunturas (timing) a la hora de proponer reformas en la relación IglesiaEstado y en el ámbito de la moral privada. Los gobiernos de UCD y del PP se caracterizaron por su postura acomodaticia hacia los intereses de la ICE, a pesar de que ninguno satisficiera en todo momento muchas de las reivindicaciones de la institución. Las políticas del PSOE relativas a educación y, sobre todo, a la moral privada han activado sin embargo el enfrentamiento. La ampliación del aborto, el "matrimonio gay" y la 
recuperación de la memoria histórica (por no hablar de los anuncios no cumplidos de laicización de la vida pública y regulación de la eutanasia) del gobierno de Rodríguez Zapatero responden a una particular agenda de reformas en el ámbito de los derechos, y se sitúan en un momento maduro de la democracia a la hora de debatir temas arriesgados que fueron aparcados anteriormente.

C) En cuanto al nivel territorial, el estado autonómico ha multiplicado los puntos de acceso al sistema político para la ICE, que se ha aprestado a través de un gran número de convenios entre los obispos y las autoridades regionales a promover sus intereses y minimizar los posibles "daños" sufridos en el nivel estatal.

En cierto sentido, podría anticiparse que la CE pudiera perder peso político a favor de los contactos bilaterales entre prelados y gobiernos regionales, más aun si se tiene en cuenta que este órgano se ha visto gradualmente controlado por el Vaticano: "bajo Juan Pablo II, algunos han cuestionado que las conferencias episcopales constituyan una forma legítima de colegialidad episcopal". Antes de llegar al papado, Ratzinger señalaba: "no debemos olvidar que las conferencias episcopales [...] no pertenecen a la estructura indispensable de la Iglesia [y por ello ninguno] de sus documentos tiene peso por sí mismo excepto por el consentimiento que se les otorga por parte de los obispos individuales" (Yamane 2005:156-7). Podría incluso hipotetizarse que en España, como ya ha sucedido en EE.UU, terminen proliferando conferencias episcopales regionales como resultado de un doble proceso: a) el carácter nacionalista de ciertas iglesias de la periferia ${ }^{18}$ y el efecto imitación por parte de otras, y b) la creciente relevancia del nivel autonómico frente al estatal para los intereses eclesiásticos ${ }^{19}$. Existe en el mundo católico una "dinámica dual de centralización (en Roma) y descentralización (en diócesis individuales) que amenaza con reducir el papel de organizaciones intermedias como las conferencias episcopales nacionales" (Yamane 2005:158).

\section{Conclusiones}

Determinados temas relativos a la moral privada, como la liberalización del aborto y el matrimonio de personas del mismo sexo, han provocado la protesta de grupos cristianos, alianzas políticas, advocacy coalitions y ciertas iglesias en Europa. La movilización social en contra de estas reformas no es sorprendente en democracia, pero sí lo es

\footnotetext{
${ }^{18}$ De hecho, existe ya una Conferencia Episcopal tarraconense. Su Concilio provincial está a la espera de aprobación por parte de la Santa Sede de una región eclesiástica tarraconense "que dará personalidad jurídica a las dos diócesis catalanas" (http://www.tarraconense.cat/index.php?inc=historia).

${ }^{19}$ Esto último se aplica también al caso norteamericano, cuyo neofederalismo, iniciado en los años ochenta, se ha plasmado, entre otras cosas, en la transferencia de la regulación sobre el aborto a los estados tras la sentencia Webster vs Servicios de Salud Reproductivos de 1989 (Yamane 2005).
} 
el muy distinto papel que las iglesias pueden desempeñar. En España, este tipo de protesta ha tenido lugar a lo largo del Gobierno de Rodríguez Zapatero y se ha caracterizado por la visible presencia de la ICE, la cual, en una alianza de facto con grupos católicos conservadores y, en menor medida, partidos políticos afines, ha desarrollado una estrategia de confrontación política. La ICE ha escogido así una estrategia similar a la de la iglesia italiana pero muy distinta a la de otras instituciones eclesiásticas europeas que se han abstenido de participar activamente en el ámbito político. Razones endógenas de carácter estructural, como la posición predominante de una iglesia con enormes recursos en una sociedad que se define mayoritariamente como católica (argumento sociológico), la inextricable relación entre catolicismo e identidad nacional (argumento histórico), y la privilegiada relación con el estado que deriva de los Acuerdos de 1979 y del aconfesionalismo constitucional (argumento institucional), pueden explicar la adopción de esta estrategia. Asimismo, las amenazas que la ICE ha percibido en la "agenda moral" del gobierno de Rodríguez Zapatero, así como la mayor definición del perfil religioso de los partidos políticos desde finales de los años noventa, constituyen razones políticas endógenas de carácter coyuntural que ayudan a dar cuenta de esta elección. Es la CE la que funciona como grupo de interés a la hora de desarrollar los contactos con el gobierno estatal, lanzar campañas mediáticas contra las reformas y apoyar las movilizaciones callejeras, pero son los obispos los que pueden desarrollar más libremente una actividad de adversario político. Sin embargo, las relaciones de los obispos con los gobiernos regionales no son generalmente conflictivas y cobran gradualmente una mayor relevancia política en detrimento de la posición a nivel estatal de la CE.

\section{REFERENCIAS BIBLIOGRÁFICAS}

Aldridge, A. 2000. Religion in the Contemporary World. Cambridge: Polity Press.

Anderson, J. 2003. "Catholicism and Democratic Consolidation in Spain and Poland." West European Politics 1 January.

Ariño, A. 2008. "Religión eclesiástica y religión común en España." en Pérez-Agote, A. y Santiago, J. Religión y Política en la Sociedad Actual, Madrid, UCM y CIS.

Barreiro, B. 2000. Democracia y conflicto moral: La política del aborto en España e Italia. Madrid: Istmo.

Bericat, E. 2008. "El escepticismo religioso y secular en Europa." Pp. 41-56 en El Fenómeno Religioso, coordinado por E. Bericat. Sevilla: Centro de Estudios Andaluces.

Berry, J. M. 1997. The Interest Group Society. New York: Longman.

Botterman, S. y M. Hooghe. 2009. "The Christian Democratic Vote and Religious Belonging." Presented at the 5th General Conference of the European Consortium for Political Research, 10-12 September, Postdam.

Callahan, W. J. 2000. The Catholic Church in Spain, 1875-1998. Washington DC: Catholic University of America Press. 
Calvo, K. 2009. "La calidad de la democracia. Las leyes de derechos civiles y la Reforma de la Política." Pp. 205-227 en La España de Zapatero, editado por Anna Bosco e Ignacio Sánchez-Cuenca. Madrid: Fundación Pablo Iglesias.

Calvo, Kerman, Martínez, Álvaro y Montero, José Ramón. 2010. "Devotos y votantes: El peso del factor religioso en las elecciones generales." Pp. 235-267 en Elecciones Generales 2008, editado por José Ramón Montero e Ignacio Lago. Madrid: CIS.

Casanova, J. 1994. Public Religions in the Modern World. Chicago-London: The University of Chicago Press.

Catela, I. 2008. Entrevistas con doce obispos españoles. Madrid: La Esfera de los Libros.

Dahl, R. A. 1961. Who Governs?. New Haven: Yale University Press.

Díaz-Salazar, R. 2005. "La estrategia de los Neo-Cons en la iglesia." Diario La Vanguardia. (http:/l firgoa.usc.es/drupal/node/22837) Consultado 28 febrero 2005.

Elzo, J. 2008. "La evolución socio-religiosa en España en los últimos 30 años." Pp. 79-98 en El fenómeno religioso, coordinado por E. Bericat. Sevilla: Centro de Estudios Andaluces.

Enyedi, Z. 2003. "Emerging Issues in the Study of Church-State Relations." West European Politics: 1 , enero.

Esping-Andersen, G. 1990. The Three Worlds of Welfare Capitalism. Cambridge: Polity Press.

Esteban, V. 2008. "La secularización en entredicho." Pp. 299-334 en El Fenómeno Religioso, coordinado por E. Bericat. Sevilla: Centro de Estudios Andaluces.

Ferrari, Lisa L. 2006. "The Vatican as a Transnational Actor." en The Catholic Church and the NationState, editado por Paul Christopher Manuel, Lawrence C. Reardon and Clyde Wilcox. 2006. Washington: Georgetown Univ. Press.

González-Anleo, J. 2008. "El post-católico español y el pluralismo religioso." Pp. 57-78 en El fenómeno reli-gioso, coordinado por E. Bericat. Sevilla: Centro de Estudios Andaluces.

González-Anleo, J. 2009. "La religiosidad española: presente y futuro." Pp. 73-98 en La Iglesia en España 1950-2000, editado por Olegario González de Cardenal. Madrid: PPC-Vida Nueva, SM.

Gurrutxaga, A. 2008. "La institución lobby: La religión en la Política." Opiniones y Actitudes 49:67-86.

Hermet, G. 1985. Los católicos en la España franquista. Madrid: CIS.

Himes, Kenneth R. 2006. "Vatican II and Contemporary Politics". Pp.15-32 en The Catholic Church and the Nation-State, editado por Paul C. Manuel, Lawrence C. Reardon y Clyde Wilcox. Washington: Georgetown Univ. Press.

Huneeus, Carlos. 1985. La Unión de Centro Democrático y la transición a la democracia en España. Madrid: $\mathrm{CIS}$.

Iglesias, Mª A. 2003. La Memoria Recuperada. Aguilar: Madrid.

Iglesias, Ma A. 2007. Cuerpo a cuerpo. Cómo son y cómo piensan los políticos españoles. Aguilar: Madrid.

Jalali, C. y J. Vargas. 2012. "Buried but not Dead? Religious Cleavage, Party Strategies and Voting in Portugal." Presentado en la Conferencia Internacional Religiosity, Ideology and Voting in Europe, 1-3 Febrero, Madrid: Mimeo. 
Katzenstein, P. J. 2006. "Multiple Modernities as Limits to Secular Europeanization?." Pp. 1-33 en Religion in an Expanding Europe, editado por Timothy A. Byrnes y Peter J. Katzenstein. Cambridge: Cambridge University Press.

Laboa, J. M. 1999. "Los hechos fundamentales ocurridos en la vida de la iglesia española en los últimos treinta años (1966-1998)." Pp.115-147 en La iglesia en España 1950-2000, editado por Olegario González de Cardenal. Madrid: PPC-Vida Nueva, SM.

Lane, Jan-Erik y S. Ersson. 1999. Politics and Society in Western Europe. London: Sage.

Lane, Jan-Erik y S. Ersson. 2005. Culture and Politics. Aldershot: Ashgate.

Lipset, S. M. and S. Rokan. 1967. Party Systems and Voter Alignments. Nueva York: The Free Press.

Madeley, John T. S. 2003. "A Framework for the Comparative Analysis of Church-State Relations in Europe." West European Politics 1, Enero.

Manuel, Paul C., Lawrence C. Reardon y C. Wilcox. 2006. The Catholic Church and the Nation-State. Washington: Georgetown Univ. Press.

Manuel, Paul C., Lawrence C. Reardon y C. Wilcox. 2006. "Introduction." Pp.1-12 en The Catholic Church and the Nation-State, editado por Paul C. Manuel, Lawrence C. Reardon y Clyde Wilcox. Washington: Georgetown Univ. Press.

Manuel, Paul C. and M. Mac Leish. 2006. "The Latin European Church." Pp. 53-68 en The Catholic Church and the Nation-State, editado por Paul C. Manuel, Lawrence C. Reardon and Clyde Wilcox. Was-hington: Georgetown Univ. Press.

Marshall, K. 2011. Religious Institutions and Global Politics. Routledge: Taylor \& Francis.

Martín, I. y Y. Tsirbas. 2011. "The Church, Moral Issues and Socialist Governments in Greece and Spain." Presentado en European Consortium for Political Research General Conference, 9-12 septiembre, Potsdam.

Mattina, L. 2010. I Gruppi di Interesse. Milano: II Mulino.

McCarthy, J. D y Mayer N. Zald. 1977. "Resource Mobilization and Social Movements." American Journal of Sociology 82:1212-39.

Minkenberg, M. 2003. "The Policy Impact of Church-State Relations: Family Policy and Abortion in Britain, France, and Germany." West European Politics 1: 195-217.

Montero, J. R., K. Calvo y Á. Martínez. 2008. "El voto religioso en España y Portugal." Revista Internacional de Sociología 51:19-54.

Norris, P. y R. Inglehart. 2004. Sacred and Secular. Cambridge: Cambridge University Press.

Ortega, J. L. 1992. "Iglesia, estado y sociedad en el Decenio Socialista." en El Decenio González, VV.AA. Madrid: Fundación Humanismo y Democracia - Ed. Encuentro.

Parkes, Geneviève. 1999. "Redefining the Legitimacy of Anti-abortion Pressure Groups in Europe." Journal of Social Welfare and Family Law 21:285-94. 
Pérez-Agote, A. y J. A. Santiago. 2005. "La situación de la religión en España a principios del siglo XXI." Pp.3-27 en Opiniones y Actitudes 49. Madrid: CIS.

Pérez-Agote, A. 2008. "La secularización de los españoles." Pp.171-192 en Opiniones y Actitudes 49. Madrid: CIS.

Pérez-Nievas, S. y G. Cordero. 2011. Religious Change in Europe (1980-2008). Presentado en IPSA International Conference, 18-20 marzo. Luxembourg.

Pérez Vilariño, J. y R. A. Schoenherr.1990. "La religión organizada en España." Pp. 449-470 en Sociedad y Política, dirigido por Salvador Giner. Madrid: Espasa-Calpe.

Requena, M. 2008. "Religión y sociedad: la secularización de la sociedad española." Pp. 319-344 en Tres décadas de cambio social en España, editado por Juan Jesús González y Miguel Requena. Madrid: Alianza Editorial.

Rinaldi, F., P. Segatti y C. Vezzoni. 2010. "Italy: Religion and Politics." Presentado en el XVII ISA World Congress of Sociology, 16 julio, Gothenburg.

Rouco, A. M. ${ }^{a}$ 1999. "Ubicación Jurídico-Social de la Iglesia en la España de Hoy." Pp. 527-550 en La Iglesia en España 1950-2000, editado por Olegario González de Cardenal. Madrid: PPC-Vida Nueva, SM.

Santiago, J. A. 2008. "Dimensión Consecuencial y Estructura Social de la Vida Religiosa en España." Pp. 193-230 en Opiniones y Actitudes 49. Madrid: CIS.

Voyé L. 2004. "A Survey of Advances in the Sociology of Religion (1980-2000)." Pp. 195-228 en New Approaches to the Study of Religion, vol. 2, editado por Peter Antes, Armin W. Geertz and Kandi R. Warne. Walter de Guyter: Berlin - Nueva York.

Warner, C. M. 2000. Confessions of an Interest Group. Princeton: Princeton University Press.

Susana Aguilar es profesora de la Universidad Complutense y doctora miembro del Instituto Juan March. Premio Memorias de Licenciatura por el Colegio Oficial de Politólogos y Sociólogos. Ha participado en numerosas investigaciones financiadas por la UE y publicado en revistas como Public Administration \& Society, Religion and Politics y The Journal of Public Policy. Su último libro publicado es Política e Identidad. Dos formas de entender la política (Alianza, 2007).

RECIBIDO: $15 / 09 / 2011$

ACEPTADO: $15 / 05 / 2012$

Publicado on-line: 08/04/2013 